\title{
A NOTE ON THE ELYTRAL PATTERN AND THE BIONOMICS OF EPILACHNA SEPTIMA IN BATTICALOA, SRI LANKA (COLEOPTERA, COCCINELLIDAE)
}

\author{
M. DHARMARETNAM ${ }^{*}$ \\ Department of Zoology, Eastern University, Chenkalady
}

(Received: 03 September 2001 ; accepted: 01 July 2002)

\begin{abstract}
Epilachninae is a phytophagous group among the Coccinellidae and some species are major pests causing extensive damage to leaves and fruits of crops. The identification of the Epilachna species found in Sri Lanka has been erroneously reported in locally available literature. Two species of Epilachna were found in Batticaloa where the study was carried out: $E$. septima on cucurbits and $E$. vigintioctopunctata on brinjal. The identification of these two species is not based on the number of black markings on the elytra as stated in local literature but on other morphological characters, which include the shape of the elytra and the genital structures. The number of black spots varies among the progeny, 6 spots being the commonest. The biology of E. septima is also presented.
\end{abstract}

Key words: Bionomics, Coccinellidae, elytral spots, Epilachna, identification, Sri Lanka.

\section{INTRODUCTION}

Subfamily Epilachninae is a herbivorous group in a largely predacious family Coccinellidae. They are pests on Cucurbitaceae and Solanaceae. Both adults and larvae cause extensive damage to leaves of host plants. Species in the genus Epilachna are typically orange to ochre in colour with a varying number of black spots on the pronotum and elytra. The genus is distributed throughout the world and includes several hundred species. Some species are considered as major pests causing extensive damage to leaves and fruits of host plants. Epilachna varivestis (Mulsant), commonly known as the Mexican bean beetle is a pest on legumes in North America; Epilachna vigintioctopunctata (Fabricius) is a pest on Solanaceae in the Oriental region from India to Australia. ${ }^{1}$

Taxonomic literature on the subfamily Epilachninae distributed in Asia include Dieke ${ }^{2}$, Kapur ${ }^{1}$ and more recently, Katakura et al. ${ }^{3}$ The identification of some species of the subfamily Epilachninae is based on the number of black spots on the elytra. For example, Epilachna kaszabi (Bielawski and Fursch) (distribution Burma and India) has six spots on each elytron ${ }^{1}$ and $E$. varivestis has eight spots on each elytron arranged in three rows. ${ }^{4}$ Accurate identification of Epilachna spp. however, is based on genital morphology. ${ }^{1}$ 
Taxonomic literature on the species belonging to the subfamily Epilachninae in Sri Lanka include that of Kapur ${ }^{1}$ which reports $E$. vigintioctopunctata (synonym E. sparsa Mulsant) and Epilachna septima Dieke (earlier described as Epilachna keiseri Bielawski). Identification of these two species is based on the morphology of genitalia as the number of black spots on the elytron vary. Bionomics of pest species of Epilachna in Sri Lanka include a report by Austin. ${ }^{5}$ He described Epilachna dodecastigmata Wiedemann (host plant snake gourd) with 6 spots on each elytron and $E$. vigintioctopunctata (host plant bitter gourd) with 14 spots on each elytron. Another early study in 1969 reports Epilachna indica (author not mentioned) infesting the bitter gourd plant. ${ }^{6}$ The Plant Protection Manual ${ }^{7}$ which is used as a text of Sri Lankan pests describes two species of Epilachna. Epilachna maculata (author not mentioned) with six black spots on each elytron and $E$. vigintioctopunctata with 14 spots on each elytron. In this manual, the number of spots on the elytra is used in species identification. The taxonomic report by Kapur ${ }^{1}$ which uses genital morphology for identification has not been referred to in the Plant Protection Manual ${ }^{7}$ published in 1978. The method of identification of Epilachna to the species level using the number of black spots on the elytra reported by Austin ${ }^{5}$ and the Plant Protection Manual ${ }^{7}$ have also been disseminated to General Certificate in Education - Advanced Level texts in Sri Lanka. ${ }^{8}$ It is reported in this paper that identification of the Epilachna species reported from Sri Lanka using the elytral spots as reported by the Plant Protection Manual is erroneous. The aim of this study was to identify some of the Epilachna species in Sri Lanka and to demonstrate that the elytral pattern varies in E. septima. Secondly, data is also presented on the bionomics of the species found in bitter gourd E. septima as it has not been described previously in Sri Lanka.

\section{METHODS AND MATERIALS}

Specimens collected from farms around Batticaloa were sent to the International Institute of Entomology, Commonwealth Agriculture Bureau, London, for identification. Batticaloa is situated in. the east coast of Sri Lanka $\left(5^{\circ} 54^{\prime}, 9^{\circ} 52^{\prime} \mathrm{N}\right.$ and $79^{\circ} 39^{\prime}, 81^{\circ} 53^{\prime} \mathrm{E}$ ) and is flat not exceeding $7.62 \mathrm{~m}$ in elevation with a tropical climate; temperature ranging from 23.6 to $35.1^{\circ} \mathrm{C}$. Stocks of $E$. septima obtained from adults and eggs from bitter gourds in farms were used in the study of bionomics. Newly emerged adults were observed till mating occurred. The mating adults were carefully removed and placed in glass jars $(2250 \mathrm{ml})$ covered with gauze. The separation of the mating individuals was possible as copulation lasted 3-5 hours. The jars contained bitter gourd leaves. The leaves were kept in water to prevent wilting and changed daily. The adults were removed once the female laid a cluster of eggs on the surface of the leaf. The maculation of the adults was noted for each individual. The eggs were counted under a microscope and their size measured using a stage micrometer. Each egg cluster was allowed to hatch. The newly hatched larvae were reared in separate insect cages with host plant leaves and allowed to develop into the adult stage. The maculation of the progeny was also noted. The larvae from 
ten egg clusters were treated as a replicate. A total of 250 larvae obtained from the ten egg clusters were used in the study of bionomics. The duration of developmental stages was noted for each replicate. The length of the larvae was also measured each day using a stage micrometer.

For the observation on the elytral spot patterns, mating adults from the first generation of offspring were again separated and the elytral spot patterns were also noted for the second generation. The frequency of elytral pattern observed in the ten egg cluster replicates for two generations (total of 510 individuals from the two generations) were noted. The basic elytral pattern (following Dieke ${ }^{2}$ ) consists of six black spots (1-6) on each elytron. This pattern may be modified by confluences between spots or the number of spots may increase by the presence of non-persistent spots $(\mathrm{a}-\mathrm{h})$.

An ambient temperature of $30-32^{\circ} \mathrm{C}$, Relative Humidity of $72 \pm 3 \%$ and a natural day length of $12 \mathrm{~L}: 12 \mathrm{D}$ cycle were recorded during the study.

\section{RESULTS}

\section{Species identification}

The species that were identified from among the specimens collected in Batticaloa, Sri Lanka, included E. septima commonly found on the bitter gourd (Momordica charantia) and E. vigintioctopunctata usually found on eggplant or brinjal (Solanum melongena). Two features can be used in the identification of $E$. septima. ${ }^{1}$ One is the shape of the elytral apex that was rounded in E. septima. The genital plate of the female of $E$. septima was deeply notched with the notched parts overlapping. In the male genitalia, the apex of the sipho was sharply narrowed on one side and pointed (Figure $1 \mathrm{a}, \mathrm{b}, \mathrm{c}$ ).

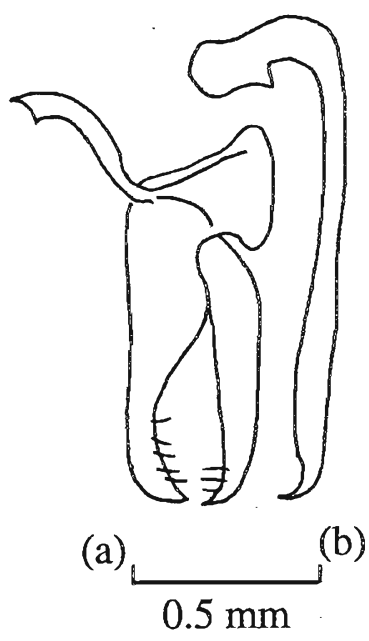




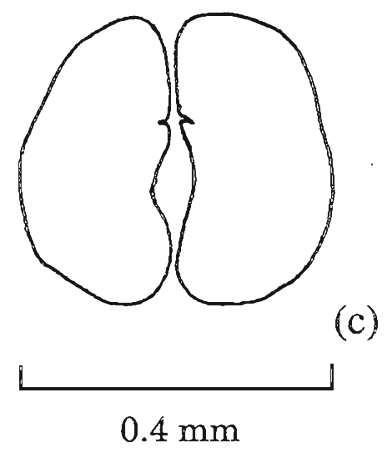

Figure 1 : a. The male genitalia of Epilachna septima except sipho.

b. The sipho of the male genitalia of $E$. septima, the apex of sipho is sharply narrowed down and pointed.

c. Female genital plates of $E$. septima, the inner margin of the genital plate is deeply notched. $(0.5 \mathrm{~mm}$ scale for Fig 1 and $b, 0.4 \mathrm{~mm}$ scale for Fig $1 \mathrm{c})$.

Table 1: The percentage of occurrence of the different elytral pattern in E. septima (from ten egg clusters and two generations, $\mathbf{n}=\mathbf{5 1 0}$ ).

\begin{tabular}{cc}
\hline Number of black spots on one elytron & Percentage occurrence \\
\hline $\begin{array}{c}5 \text { spots } 1 \text { missing } \\
\text { (normal and } 3+5)\end{array}$ & 8 \\
6 spots & 56 \\
(normal, $3+5$ and $3+4+5)$ & 12 \\
7 spots & \\
$(6+c, 6+h)$ & 28 \\
8 spots & \\
$(6+\mathrm{e}, \mathrm{f})(6+\mathrm{c}, \mathrm{f})$ & 6 \\
9 spots & \\
$(6+\mathrm{a}, \mathrm{d}, \mathrm{h})$ & 8 \\
10 & 2 \\
$(6+\mathrm{c}, \mathrm{d}, \mathrm{e}, \mathrm{g})(\mathrm{a}, \mathrm{e}, \mathrm{f}, \mathrm{h})$ & \\
11 & \\
$(6+\mathrm{a}, \mathrm{c}, \mathrm{d}, \mathrm{g}, \mathrm{h})$ & \\
\hline
\end{tabular}

\section{Maculation of $E$. septima}

Head spotless; pronotum with two to six spots. The number of black spots on each elytron varied from $5-11$ among the progeny obtained (Table 1 ). Confluence of spots 
$3+5$ and $3+4+5$ and non-persistent spots a, c, d, e, f, g and h occurred. Thus, a total of 13 different types of elytral pattern combinations were noted among the progeny of $E$. septima. For brevity, the number of spots on the elytra numbering five to eleven was taken for data presentation rather than 13 different combinations. The six spot pattern was observed in $56 \%$ of the progeny, followed by 8 spot pattern $(28 \%)$.

\section{Bionomics of E. septima}

The adult size (length) was 6.1 to $7.1 \mathrm{~mm}$ (male) and 7.0 to 7.6 (female) $\mathrm{mm}$. Copulation lasted 3-5 hours. Egg clusters were laid 1-2 days after copulation (Table 2). The eggs were laid in mass in an erect position on the underside of leaves. The egg mass was triangular or diamond shaped; 35-50 eggs were laid in each mass. Each female laid a total ranging from 120-320 eggs. The eggs were yellow in colour with circular depression like markings on their surface. The average size of a single egg was $1.5 \times 0.5 \mathrm{~mm}$. A circular operculum was present in the anterior end of the egg. The incubation period was 2-6 days. The egg hatching period was 4-6 hours.

Table 2: A summary of the bionomics of $E$. septima.

\begin{tabular}{|c|c|c|}
\hline \multicolumn{2}{|c|}{ Range } & \multirow{2}{*}{$\begin{array}{r}\text { Mean } \pm \text { S.E } \\
43.2 \pm 2.07\end{array}$} \\
\hline No of eggs/cluster & $35-50$ & \\
\hline Size (length) of egg (mm) & $1.5-0.5$ & $1.2 \pm 0.4$ \\
\hline Length of first instar larvae (mm) & $1.0-1.4$ & $1.19 \pm 0.035$ \\
\hline Length of last instar (mm) & $8.0-9.4$ & $8.79 \pm 0.14$ \\
\hline Incubation period (days) & $2-5$ & $3.7 \pm 0.75$ \\
\hline First instar (days) & $3-6$ & $3.2 \pm 0.23$ \\
\hline Second instar (days) & $2-3$ & $2.9 \pm 0.07$ \\
\hline Third instar (days) & $2-3$ & $2.9 \pm 0.07$ \\
\hline Fourth instar (days) & $4-5$ & $4.4 \pm 0.14$ \\
\hline Total larval period (days) & $13-14$ & $13.2 \pm 0.44$ \\
\hline Pupal period (days) & $3-5$ & $3.8 \pm 0.60$ \\
\hline Life cycle (total) (days) & $18-24$ & $20.92 \pm 1.11$ \\
\hline
\end{tabular}

Newly hatched larvae were pale yellow in colour and the length ranged from $1.0-1.4 \mathrm{~mm}$. Typical for the species, the larvae had tubercles on their body from which branched spines arose. The spines were found in both the thoracic (3) and 
abdominal (9) segments. A dorsal and two lateral rows of spines were found in each segment. In the first instar larvae, branched spines were found only on the dorsal row and the lateral rows of the pro and meso thoracic segments. After the first moult, all spines became branched. Furthermore, an additional lateral row of spines beneath the existing lateral row developed in the last 8 abauminal segments after the first moult. The tip of the spines darkened after 3-4 days. The larval period ranged from 13-14 days (Table 2). Moulting of larvae occurred three times on the $3^{\text {rd }}, 6^{\text {th }}$ and $9^{\text {th }}$ days after hatching. The colour of the larvae also became a darker shade of yellow with each moult. The larval size ranged from 1.19- $8.8 \mathrm{~mm}$ from the first to fourth instar. The last larval moult skin was attached to the posterior end of the pupa. The pupal stage occupied 3-5 days. The newly emerged adult was pale yellow and within one hour it turned darker and the black spots on the elytra appeared.

\section{DISCUSSION}

The number of markings on the elytra varied in the specimens of E. septima collected from Batticaloa, Sri Lanka. Thus, there is a need for correction of the identification method in the Plant Protection Manual ${ }^{7}$ and other locally used texts. For identification of Epilachna species dissection of the genitalia is necessary. One of the species mentioned in the Plant Protection Manual ${ }^{7}$ E. maculata was not found in the literature. ${ }^{1,2,3}$ According to the literature available, Epilachna macularis Mulsant distributed in North India and China and Epilachna vigintioctomaculata Motschulsky complex in the Japanese archipelago ${ }^{9}$ are mentioned. E. maculata mentioned in the Plant Protection $\mathrm{Manual}^{7}$ could not be traced to any other reference. Wijeyaratnam ${ }^{6}$ has made reference to $E$. indica (a synonym was not found in any other literature ${ }^{1,2,3}$ ) and since $E$. septima is the only species that infests bitter gourd as the host plant ${ }^{10,11} E$. indica ${ }^{6}$ probably refers to $E$. septima. Kapur ${ }^{1}$ refers to a species Epilachna dodecastigma Wiedeman which is now considered incorrect ${ }^{11}$ and this species is now referred to as Epilachna pusillanima Mulsant ${ }^{12}$ and is a pest on cucurbitaceous plants such as squash (Cucurbita moschata), wax gourd (Benincasa cerifera) and Lufa cylindrica. ${ }^{1,12}$ E. dodecastigma described by Austin ${ }^{5}$ on snake gourd was probably $E$. pusillanima.

The elytral spots or melanization has been shown to be influenced by genetic factors as well as environmental factors such as ambient temperatures.$^{13}$ The most common elytral pattern of $E$. septima in our study was the six spot combination. E. septima reported from Sumatra and Java had 14 spots. $^{3}$ A study on the biology of E.septima in India reports 8-15 spots on each elytron..$^{13}$ This difference may be due to inter and intra-populational variation in elytral spot pattern as has been shown in E.vigintioctopunctata. ${ }^{15}$ In this study ${ }^{15}$, the number of spots on the elytra increased with altitude. 
The biology of $E$. septima of this study is comparable to a study on the biology of E.septima reported from India. ${ }^{13}$ The incubation period ranged from 3-4 days in their study ${ }^{13}$ and 2-5 in this study. The total larval period ranged from 14-23 days in the study done in India ${ }^{13}$ and was lower by 13-14 days in this study. As the average was not given in the study done in India ${ }^{13}$ it is difficult to make a comparison. The pupal period in the study done in India ${ }^{13}$ was 3-4 days and it was 3-5 days in this study. It is possible that the variety of bitter gourd may have also affected the bionomics of E.septima. It has been observed that E.septima exhibits a longer lifespan on the short variety of bitter gourd compared to the long variety. ${ }^{14}$

Host specificity is pervasive in Epilachna species. This is considered one of the mechanisms by which reproductive isolation occurs in sympatric species. ${ }^{16}$ E. septima was only found on bitter gourd (Momordica charantia) whereas $E$. vigintioctopunctata was found on solanceous plants, the egg plant in the author's observations. In fact $E$. vigintioctopunctata collected in Indonesia, Malaysia, Thailand and Japan was unable to complete its lifecycle on cueurbitaceous plants. ${ }^{17}$

There is a need for a comprehensive survey of the Epilachnae occurring in Sri Lanka as the author's collection was restricted to the Batticaloa district. There may be a geographic variation in the elytral pattern as shown in the study in Indonesia. ${ }^{18}$ Finally, knowledge on the identification, host preferences and geographical distribution of the Epilachna group is important not only from an evolutionary point of view but also for an effective pest management programme.

\section{Acknowledgement}

I am grateful to Dr. R. G. Booth of CAB International for identification and providing literature and comments. I also wish to thank Prof. H. Katakura for providing me with recent literature. I also wish to express my sincere thanks to the two referees for their valuable comments on the manuscript.

\section{References}

1 Kapur A.P. (1967). The Coccinellidae (Coleoptera) of the Andamans. Proceedings of the National Institute Of Sciences of India 32B: 148-189.

2 Dieke G.H. (1947). Ladybeetles of the genus Epilachna in Asia, Europe and Australia. Smithsonian Miscellaneous Collections 106:1-183.

3 Katakura H., Nakano S., Kahono S., Abbas I \& Nakamura K. (2001). Epilachnine Ladybird Beetles (Coleoptera, Coccinellidae) of Sumatra and Java. Tropics 10(3): 325-352. 
4 Robert M. (1950). Entomology for Introductory Courses. International Books and Periodicals Supply Service: 370-371

5 Austin G.D. (1925). Some beetle pests of cucurbits in Ceylon. Yearbook of Agriculture Ceylon: 41-47.

6 Wijeyaratnam P.M. (1969). Some preliminary studies on Epilachna indica (Coleoptera: Coccinnellidae, infesting bitter gourd plant (Mormordica charantia) of Ceylon. Proceedings of the Ceylon Association for the Advancement of Science :66.

7 Karandawela C.B \& Manickavasagar P. (1978). The identification and control of some pests of vegetables. In Plant Protection Manual. Dept of Agriculture, Peradeniya. Peradeniya, Sri Lanka: 35-36.

8 Selvanayagam S. \& Francis M.C. (1982). Pests for G.C.E (A/L). Bastian Press, Jaffna.

9 Shirai Y. \& Katakura H. (1999). Host plants of the phytophagous ladybird beetle, Epilachna vigintioctopunctata (Coleoptera: Coccinellidae), in Southeast Asia and Japan. Applied Entomological Zoology, 34(1): 75-83.

10 Booth R.G \& Pope R.D. (1989). A review of the type material of Coccinellidae (Coleoptera) described by F.W. Hope and by E. Mulsant in the Hope Entomological Collections, Oxford. Entomologica Scandinavia 23: 343-370.

11 Sreekala S. \& Ushakumari R. (1999). Epilachna beetles infesting vegetables in Kerala, India. Insect-Environment 5(2): 55-56.

12 Nakano S. \& Katakura H. (1999). Morphology and biology of a phytophagous ladybird beetle, Epilach̆na pusillanima (Coleoptera: Coccinellidae) newly recorded on Ishigaki island, the Ryukyus. Applied Entomological Zoology 34: 189-194.

13 Mahalya J.L \& Jesudasan A.R.W. (1996). Biology of Epilachna septima Dieke (Coccinellidae: Coleoptera, infesting Momordica charantia with a note on its feeding damage. Uttar Pradesh Journal of Zoology 16(2): 83-86.

14 Patel P.C., Patel J.K \& Patel J.C. (1967). A bitter gourd variety resistant to epilachnine beetle Epilachna septima Dieke. Indian Journal of Entomology 29(3): 237-248. 
15 Koizumi T., Fujiyama N \& Katakura H. (1999). Host plant specificity limits the geographic distribution of thistle feeding ladybird beetles. Entomologia Experimentalis et Applicata 93: 165-171.

16. Abbas I., Nakamura K., Katakura H \& Sasaji H. (1988). Geographic variation of elytral spot patterns in the phytophagous ladybird, Epilachna vigintioctopunctata (Coleoptera: Coccinellidae) in the Province of Sumatra Barat, Indonesia. Population Ecology 30:43-56.

17. Ueno H., Hasegawa Y., Fujiyama N \& Katakura H. (2001). Comparison of genetic variation in growth performance on normal and novel host plants in a local population of a herbivorous ladybird beetle, Epilachna vigintioctomaculata. Heredity 87: 1-7.

18. Katakura H., Saitoh S., Nakamura K \& Abbas I. (1994). Multivariate analyses of elytral spot patterns in the phytophagous ladybird beetle Epilachna vigintioctopunctata (Coleoptera, Coccinellidae) in the Province of Sumatra 